\title{
Surgical site infection after wound closure with staples versus sutures in elective knee and hip arthroplasty: a systematic review and meta-analysis
}

\author{
A. van de Kuit ${ }^{1}$, , R. J. Krishnan² ${ }^{2}$, W. H. Mallee ${ }^{3}$, L. M. Goedhart ${ }^{4}$, B. Lambert ${ }^{4}$, J. N. Doornberg ${ }^{4 *}$,
}

T. M. J. S. Vervest ${ }^{5}$ and J. Martin ${ }^{2}$

\begin{abstract}
Purpose: This systematic review and meta-analysis aimed to study surgical site infection of wound closure using staples versus sutures in elective knee and hip arthroplasties.

Methods: A systematic literature review was performed to search for randomized controlled trials that compared surgical site infection after wound closure using staples versus sutures in elective knee and hip arthroplasties. The primary outcome was surgical site infection. The risk of bias was assessed with the Cochrane risk of bias assessment tool. The relative risk and 95\% confidence interval with a random-effects model were assessed.

Results: Eight studies were included in this study, including 2 studies with a low risk of bias, 4 studies having 'some concerns', and 2 studies with high risk of bias. Significant difference was not found in the risk of SSI for patients with staples $(n=557)$ versus sutures $(n=573)\left(R R: 1.70,95 \% \mathrm{Cl}: 0.94-3.08, l^{2}=16 \%\right)$. The results were similar after excluding the studies with a high risk of bias (RR: $1.67,95 \% \mathrm{Cl}: 0.91-3.07, \mathrm{I}^{2}=32 \%$ ). Analysis of studies with low risk of bias revealed a significantly higher risk of surgical site infection in patients with staples $(n=331)$ compared to sutures $(n=331)$ (RR: $2.56,95 \% \mathrm{Cl}: 1.20-5.44, \mathrm{I}^{2}=0 \%$ ). There was no difference between continuous and interrupted sutures $(P>0.05)$. In hip arthroplasty, stapling carried a significantly higher risk of surgical site infection than suturing (RR: 2.51 , $95 \% \mathrm{Cl}: 1.15-5.50, \mathrm{I}^{2}=0 \%$ ), but there was no significant difference in knee arthroplasty (RR: $0.87,95 \% \mathrm{Cl}: 0.33-2.25$, $\left.\mathrm{I}^{2}=22 \% ; P>0.05\right)$.
\end{abstract}

Conclusions: Stapling might carry a higher risk of surgical site infection than suturing in elective knee and hip arthroplasties, especially in hip arthroplasty.

Keywords: Surgical site infection, Wound closure, Total knee replacement, Total hip replacement, Arthroplasty, Systematic review

*Correspondence: j.n.doorberg@umcg.nl

${ }^{4}$ Department of Orthopaedics, University Medical Center Groningen, Postbus 30.001, 9700 RB Groningen, The Netherlands

Full list of author information is available at the end of the article

\section{Background}

In arthroplasty, surgical site infections (SSI) are an important problem associated with prosthetic joint infection, prolonged hospitalization, reoperation, readmission, increased mortality rates and increased healthcare costs $[1,2]$. To prevent SSI, the World Health Organization (WHO) released the global guidelines (2016) for the 
use of antimicrobial-coated sutures [3]. However, the guidelines do not address the ongoing debate of stapling versus suturing in wound closure.

Owing to the low incidence of SSI, many randomized controlled trials (RCT) are underpowered and devaluated with a high risk of bias. Krishnan and colleagues indicated that patients in orthopedic and trauma surgery randomized to staples had a higher risk of SSI compared to patients randomized to sutures (RR, 2.05; 95\% CI,1.38 to 3.06) [4]. However, there was no significant difference after excluding the studies with a high risk of bias [4]. Furthermore, both elective and trauma cases were included, causing heterogeneity in the study population because post-traumatic skin perfusion and wound healing are more difficult [5].

Recently, Mallee et al. [6] published the largest RCT in patients undergoing elective hip arthroplasty. This study showed a nearly three times greater risk of SSI after wound closure using staples versus sutures [6]. Given this recent evidence and the potential implications for SSI in patients undergoing arthroplasty in the elective setting, an analysis of available evidence is warranted. Therefore, we raised 4 questions: (1) Are staples or sutures associated with higher risk of SSI? (2) Do the results change when the analysis is limited to studies with a low risk of bias? (3) Do the outcomes differ between continuous and interrupted sutures? and (4) Do outcomes differ between hip and knee arthroplasties?

\section{Methods}

We performed a systematic review and meta-analysis of RCT on SSI after primary hip and knee arthroplasties. We compared the risks of stapling versus suturing. The study was performed according to the Cochrane guidelines [7] and reported following the Preferred Reporting Items for Systematic Reviews and Meta-Analysis guidelines (PRISMA) guidelines [8].

\section{Primary outcome}

Our primary outcome was SSI, defined as either superficial or deep infections. If the authors did not specify if infection is superficial or deep, we included their reported SSI. In case both categories were described, we assumed that we could combine the cases. When SSI was reported at multiple time points, the one with the longest available follow-up time was selected.

\section{Search strategy and study selection}

We systematically searched the electronic databases PubMed, Embase, Cinahl, Cochrane, Google Scholar and Web of Science (Table S1 of the Appendix). Furthermore, we searched the first 15 pages of Google to identify potential studies that were not included in the databases mentioned above or had been published in non-indexed journals. Our final search was conducted on December 23, 2020. Then, two researchers (RK and AK) independently assessed the studies. Our inclusion criteria were: (1) RCTs; (2) adult patients (>18 years of age); (3) elective knee and hip arthroplasties; (4) studies comparing stapling and suturing, and (5) reporting SSI as an outcome. The exclusion criteria were: (1) a barbed suture method because it was different from the methods mentioned above, (2) the use of synthetic adhesives such as 2-octyl cyanoacrylate; and (3) mixed populations (both trauma and elective surgery). A third researcher (JD) was available for resolving disputes about the eligibility of inclusion.

\section{Data extraction}

One author (AK) extracted the data from the included studies. The second author (RK) verified the included data. We translated non-English trials using Google Translate. If there were questions about the (possibly) included studies, we personally communicated with the corresponding authors.

\section{Risk of bias}

Using the Cochrane risk of bias assessment tool 2.0, we assessed the outcomes of the included studies to find an overall risk-of-bias score [9]. Algorithms were used to determine the risk of bias per domain and the overall risk of bias score. Three independent researchers (LG, $\mathrm{BL}$ and $\mathrm{AK}$ ) assessed the risk of bias for included RCTs. Discrepancies were solved by comparing notes. A fourth researcher (JD) was available for resolving the disputes about biases.

\section{Statistical analysis}

Statistical analysis was conducted using Review Manager (RevMan), version 5.4 (The Nordic Cochrane Centre, The Cochrane Collaboration, 2009, Copenhagen, Denmark) and Stata 15 (StataCorp LP, College Station, TX, USA). We calculated relative risk (RR) and 95\% confidence interval (CI) with a random effects model [10]. We explored the publication bias using funnel plots and Egger's regression test. Statistical heterogeneity was quantified by using the $\mathrm{I}^{2}$ value. A value equal to $40 \%$ or more was considered to be substantial heterogeneity [7]. Pre-planned subgroup analysis included a comparison between stapling and continuous and interrupted suturing in hip and knee arthroplasties. We used post hoc subgroup analyses to explore the effect size. Differences across subgroups were interpreted through the test for subgroup interaction, where a conservative threshold of $P<0.10$ was used to indicate significant differences across subgroup effect sizes since tests for subgroup interactions 


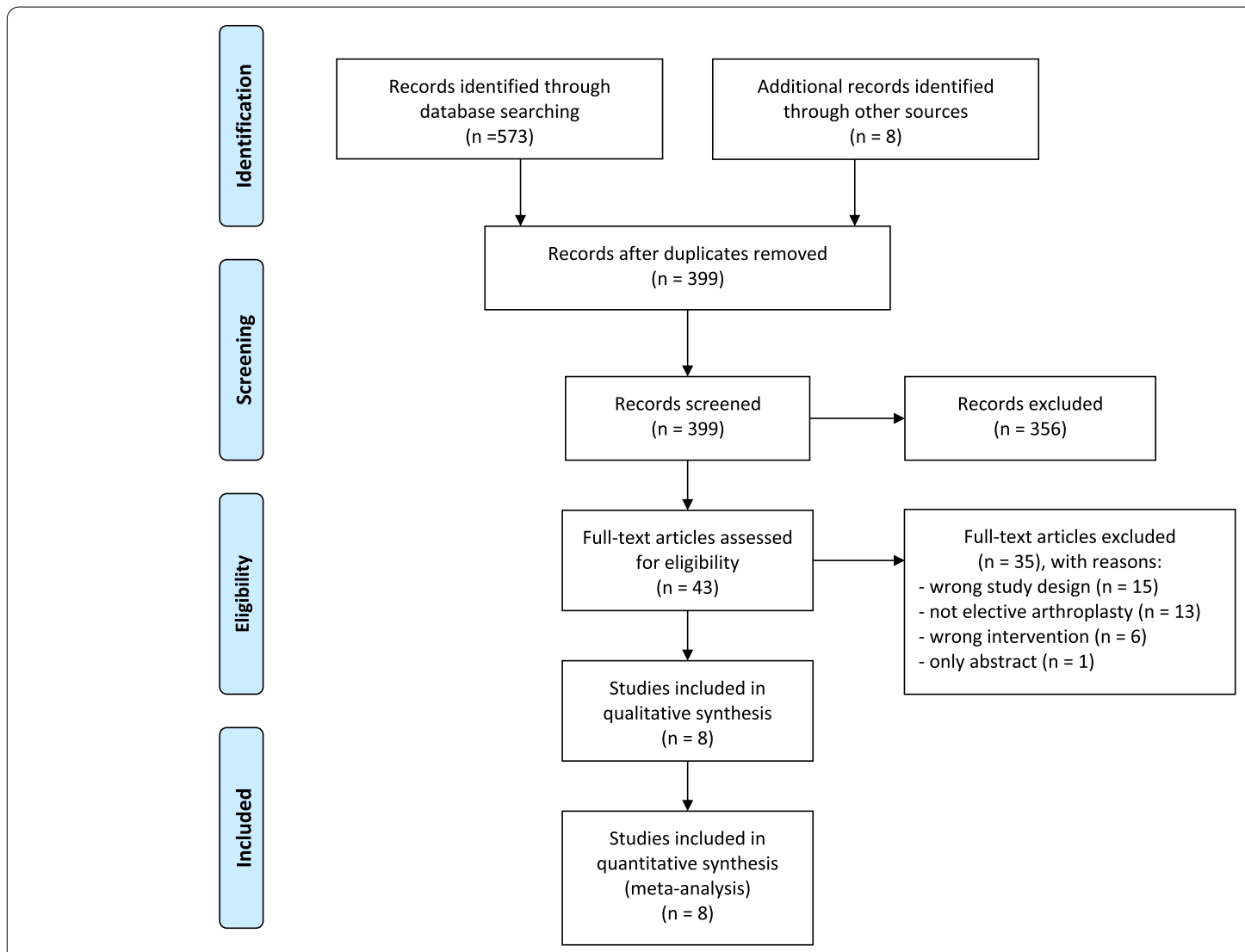

Fig. 1 Flow of the identified studies

are typically underpowered. Sensitivity analyses were performed to assess whether conclusions were affected when studies with "some concerns" or "high risk of bias" were excluded.

\section{Results}

Our systematic search retrieved 399 unique studies (Fig. 1), and 356 of them were excluded based on title and abstract screening. After reading the full text, we excluded another 35 studies with erroneous study design or intervention (Table 2 of the Appendix). Finally, a total of 8 studies met the inclusion criteria (Table 1) [6, 1117]. One of them was not available in English and was translated using Google Translate [14]. We extracted predefined study characteristics and the incidence of SSI in both groups.

\section{Study characteristics}

In the 8 RCTs, 5 studies focused on knee arthroplasty [12-14, 16, 17], 2 studies on hip arthroplasty [6, 11], and 1 study on both hip and knee arthroplasty [15]. A total of 1130 patients (stapling in 557 patients and suturing in 573 patients) were included in the meta-analysis. In
2 studies, SSI was the primary outcome $[6,15]$. In the remaining 6 studies, SSI was described as one of the secondary outcomes. The incidence of SSI varied from 0 to $15.7 \%$. We did not observe wound complications or SSI in 2 studies [13, 17]. A clear description of SSI was reported in 2 studies $[6,15]$. The remaining 6 studies did not provide a clear definition of SSI. Absorbable sutures were used in 5 studies and non-absorbable sutures were used in 3 studies $[6,11,16]$. The follow-up period ranged from 7 days to 1 year.

\section{Risk of Bias}

Two studies had low risk of bias [6, 15], 4 studies had 'some concerns' [11, 12, 16, 17], and 2 studies had high risk of bias $[13,14]$. Owing to the intervention nature, blinding of patients and outcome assessors was impossible in all studies. In 2 studies, the authors tried to prevent bias by blinding the outcome assessor or statistician [6, 15]. In 1 study, the follow-up lasted for 7 days, which was insufficient for detecting SSI [13]. The important reasons for being rated as high risk were the concerns about SSI detected (Appendix Table 3 and 4). In many studies [11$14,16,17]$, there was lack of description of SSI, which 


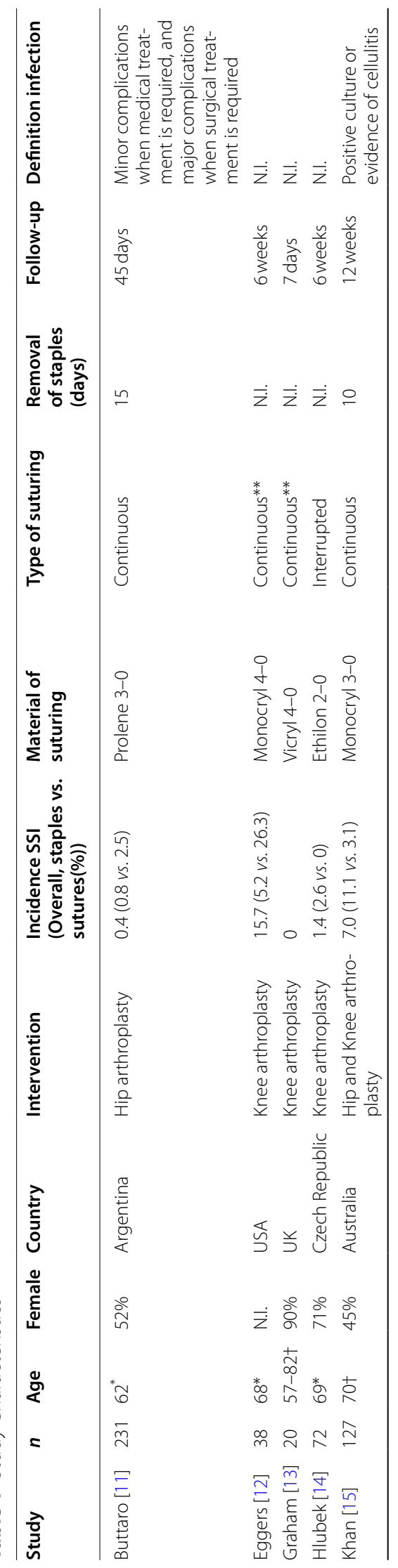




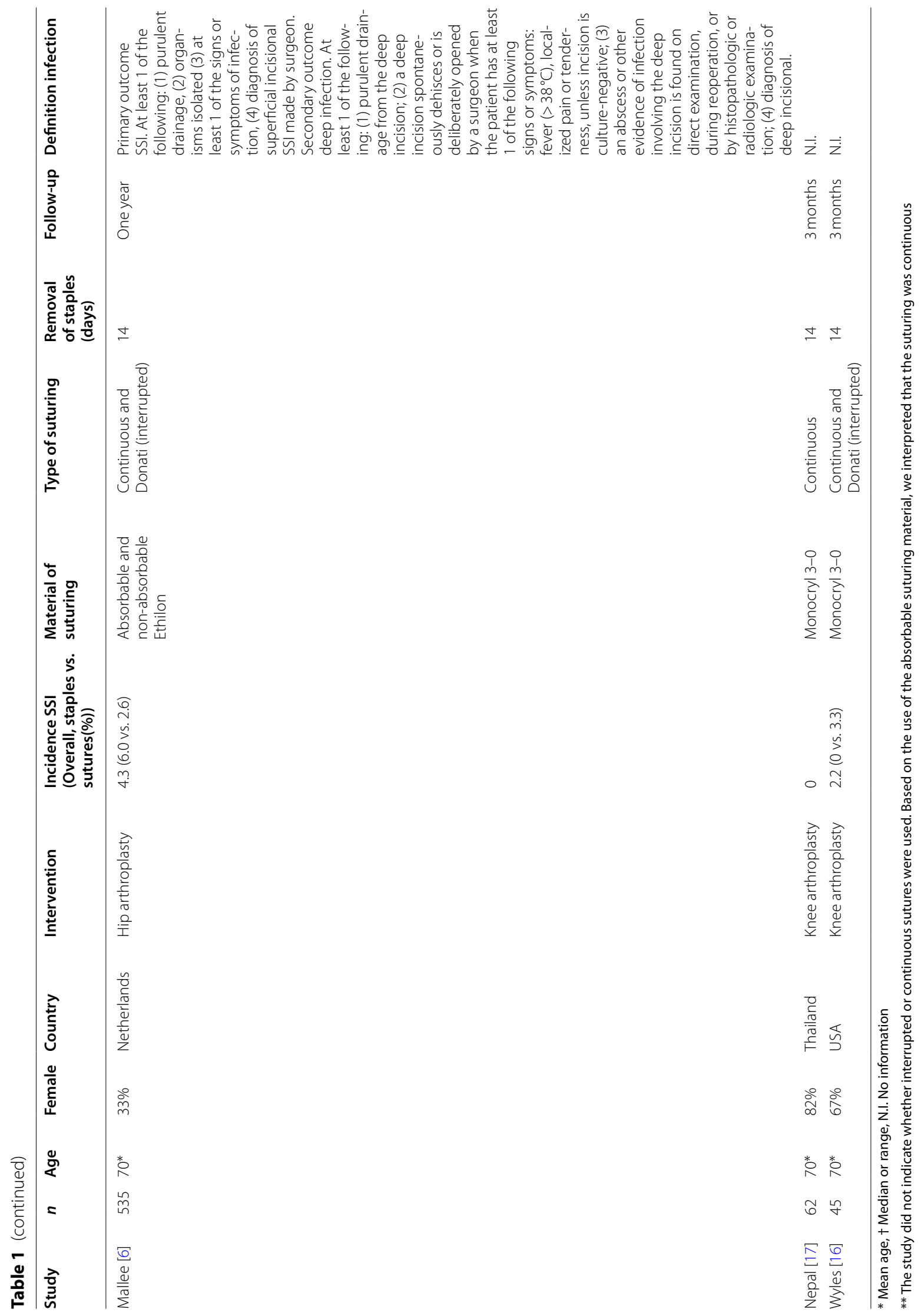


influenced the intervention. Other concerns included the lack of information about the randomization process or predictable allocation sequence (quasi-randomization) (Table 2).

\section{Meta-analysis}

In all RCTs combined, we did not find a significant difference in the risks of SSI between suturing $(n=557)$ and stapling $(n=573)$ (RR: $1.70,95 \%$ CI: $0.94-3.08, \mathrm{I}^{2}=16 \%$ ) (Fig. 2A). The results were similar after excluding the studies with high risk of bias, where we did not find a significant difference between stapling $(n=508)$ and suturing $(n=530)$ (RR: $1.67,95 \%$ CI: $0.91-3.07, \mathrm{I}^{2}=32 \%$ ) (Fig. 2B). When the analysis was limited to the studies with a low risk of bias (Mallee et al. and Khan et al.), we found a significantly higher risk of SSI for patients treated with staples $(n=331)$ compared to sutures $(n=331)$ (RR: 2.56, 95\% CI: 1.20-5.44, $\mathrm{I}^{2}=0 \%$ ) (Fig. 2C).

Subgroup analyses did not suggest significant differences in the risks of SSI between staples and interrupted

Table 2 Risk of Bias in the included studies

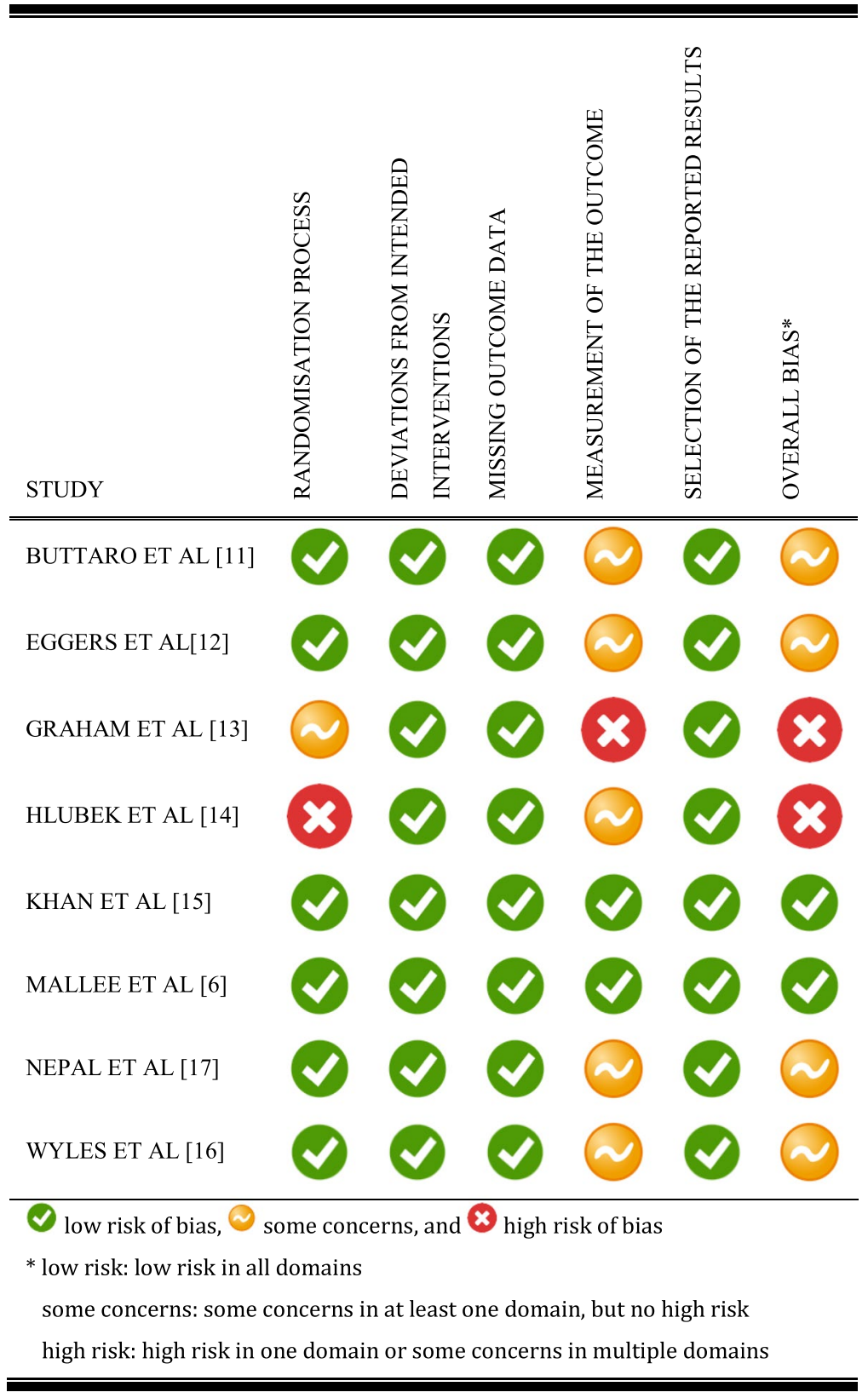




\begin{tabular}{|c|c|c|c|c|c|c|c|c|c|c|c|}
\hline \multirow[t]{12}{*}{ A } & Study or Subgroup & \multicolumn{2}{|c|}{ Staples } & \multicolumn{2}{|c|}{ Sutures } & Weight & \multirow{2}{*}{$\begin{array}{c}\begin{array}{c}\text { Risk Ratio } \\
\text { M-H, Fixed, 95\% Cl }\end{array} \\
2.13[0.20,23.11]\end{array}$} & \multicolumn{4}{|c|}{$\begin{array}{c}\text { Risk Ratio } \\
\text { M-H, Fixed, 95\% CI } \\
\end{array}$} \\
\hline & Buttaro 2015 & 2 & 112 & 1 & 119 & $5.9 \%$ & & & & & \\
\hline & Eggers 2011 & 1 & 19 & 5 & 19 & $30.3 \%$ & $0.20[0.03,1.55]$ & & 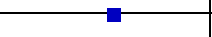 & & \\
\hline & Graham 2000 & 0 & 10 & 0 & 10 & & Not estimable & & & & \\
\hline & Hlubek 2014 & 1 & 39 & 0 & 33 & $3.3 \%$ & $2.55[0.11,60.57]$ & & & & \\
\hline & Khan 2006 & 7 & 63 & 2 & 64 & $12.0 \%$ & $3.56[0.77,16.46]$ & & & & \\
\hline & Mallee 2020 & 16 & 268 & 7 & 267 & $42.4 \%$ & $2.28[0.95,5.45]$ & & & & \\
\hline & Nepal 2020 & 0 & 31 & 0 & 31 & & Not estimable & & & & \\
\hline & Wyles 2016 & 0 & 15 & 1 & 30 & $6.2 \%$ & $0.65[0.03,14.97]$ & & & & \\
\hline & Total $(95 \% \mathrm{Cl})$ & & 557 & & 573 & $100.0 \%$ & $1.70[0.94,3.08]$ & & & & \\
\hline & Total events & 27 & & 16 & & & & & & & \\
\hline & $\begin{array}{l}\text { Heterogeneity: } \mathrm{Chi}^{2}= \\
\text { Test for overall effect }\end{array}$ & $\begin{array}{l}5.97, \mathrm{df} \\
\mathrm{Z}=1.75\end{array}$ & $\begin{array}{l}=5(P \\
(P=0\end{array}$ & $\begin{array}{l}=0.31) \text {; } \\
0.08)\end{array}$ & $I^{2}=16$ & & & 0.01 & $\begin{array}{c}0.1 \\
\text { Favours Staples }\end{array}$ & $\begin{array}{c}10 \\
\text { urs Sutures }\end{array}$ & 100 \\
\hline \multirow{11}{*}{ B } & & Staple & & Sutur & & & Risk Ratio & & Risk R & Ratio & \\
\hline & Study or Subgroup & Events & Total & Events & Total & Weight & M-H, Fixed, 95\% Cl & & M-H, Fixe & d, $95 \% \mathrm{Cl}$ & \\
\hline & Buttaro 2015 & 2 & 112 & 1 & 119 & $6.1 \%$ & $2.13[0.20,23.11]$ & & & & \\
\hline & Eggers 2011 & 1 & 19 & 5 & 19 & $31.3 \%$ & $0.20[0.03,1.55]$ & & 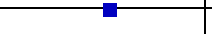 & - & \\
\hline & Khan 2006 & 7 & 63 & 2 & 64 & $12.4 \%$ & $3.56[0.77,16.46]$ & & & & \\
\hline & Mallee 2020 & 16 & 268 & 7 & 267 & $43.9 \%$ & $2.28[0.95,5.45]$ & & & & \\
\hline & Nepal 2020 & 0 & 31 & 0 & 31 & & Not estimable & & & & \\
\hline & Wyles 2016 & 0 & 15 & 1 & 30 & $6.4 \%$ & $0.65[0.03,14.97]$ & & & & \\
\hline & Total $(95 \% \mathrm{Cl})$ & & 508 & & 530 & $100.0 \%$ & $1.67[0.91,3.07]$ & & & & \\
\hline & Total events & 26 & & 16 & & & & & & & \\
\hline & Heterogeneity: $\mathrm{Chi}^{2}=$ & $5.92, \mathrm{df}=$ & $=4(\mathrm{P}$ & $=0.21) ;$ & $1^{2}=32$ & & & 0.01 & 0.1 & 10 & 100 \\
\hline & & & & & & & & & c & & \\
\hline \multirow{7}{*}{ C } & & Staple & & Sutur & & & Risk Ratio & & Risk R & Ratio & \\
\hline & Study or Subgroup & Events & Total & Events & Total & Weight & $\mathrm{M}-\mathrm{H}$, Fixed, $95 \% \mathrm{Cl}$ & & M-H, Fixec & d, $95 \% \mathrm{Cl}$ & \\
\hline & Khan 2006 & 7 & 63 & 2 & 64 & $22.1 \%$ & $3.56[0.77,16.46]$ & & & & \\
\hline & Mallee 2020 & 16 & 268 & 7 & 267 & $77.9 \%$ & $2.28[0.95,5.45]$ & & & & \\
\hline & Total $(95 \% \mathrm{Cl})$ & & 331 & & 331 & $100.0 \%$ & $2.56[1.20,5.44]$ & & & & \\
\hline & Total events & 23 & & 9 & & & & & & & \\
\hline & $\begin{array}{l}\text { Heterogeneity: } \mathrm{Chi}^{2}= \\
\text { Test for overall effect }\end{array}$ & $\begin{array}{l}0.25, \mathrm{df}= \\
\mathrm{Z}=2.44\end{array}$ & $\begin{array}{l}=1(P \\
(P=0\end{array}$ & $\begin{array}{l}=0.62) \text {; } \\
0.01)\end{array}$ & $1^{2}=0 \%$ & & & 0.01 & $\begin{array}{c}0.1 \\
\text { Favours Staples }\end{array}$ & $\begin{array}{c}10 \\
\text { Favours Sutures }\end{array}$ & $100^{\circ}$ \\
\hline
\end{tabular}

sutures and between staples and continuous sutures $(P$ value for subgroup interaction $=0.99)($ Fig. S1). For the hip arthroplasty subgroup, staples were associated with an increased risk of SSI compared to sutures (RR: 2.51, 95\% CI: $1.15-5.50, \mathrm{I}^{2}=0 \%$ ), but there was no difference in knee arthroplasty (RR:0.87, 95\% CI: 0.33-2.25, $\left.\mathrm{I}^{2}=22 \%\right)$. The test for interaction across subgroups indicated a significant difference in effect size between the two subgroups ( $P$ value for subgroup interaction $=0.09$ ) (Fig. S2). Statistical analysis of publication bias was not feasible because the number of our studies was smaller than 10 [7].

\section{Discussion}

In this systematic review and meta-analysis, we assessed the risk of SSI after primary wound closure with staples versus sutures in elective knee and hip arthroplasty. Our primary findings suggest that wound closure with staples carries a higher risk of SSI than sutures. Furthermore, we showed that the subgroup of patients undergoing hip arthroplasty may have a higher risk of SSI when treated with staples, but no difference was found for knee arthroplasty. However, given the low power in this meta-analysis and the heterogeneity of SSI definitions, the results remain non-definitive.

This is the first meta-analysis that focused primarily on wound closure with staples and sutures in elective hip and knee arthroplasties. Previous reviews focused on heterogeneous groups, including both trauma as well as elective patients, or focused on other closing materials such as barbed sutures $[4,18-20]$. The strength of our study includes a large number of patients (1130 patients), a relatively sufficient number of RCTs (8 studies), and study of elective arthroplasties. Using the Cochrane risk of bias assessment tool 2.0, we assessed, in detail, the risks of bias based on the 5 different domains, and 
conducted a sensitivity analysis by excluding the studies with a higher risk of bias.

The major limitation of this systematic review is the lack of high-quality and adequately-powered studies in arthroplasty. Future studies should primarily focus on SSI, more clearly describe the outcomes (e.g., definitive data from Centers for Disease Control and Prevention and at least 1 year follow-up to detect all potentially serious SSI), and have definitive results based on larger sample size. Second, double blinding was largely absent in the included studies due to the nature of the interventions but should be possible for the statistician in future studies. Third, the heterogeneous population (including both knee and hip arthroplasties) and different postoperative wound managements and healing processes decrease the power of the meta-analysis, resulting in a non-definitive conclusion [5].

Joint arthroplasty remains one of the most common surgical procedures and is a significant contributor to SSI burden worldwide. It is crucial to identify the interventions to reduce the risk of SSI. When choosing a wound closure method, we should consider these factors, including availability, familiarity, affordability, costeffectiveness, cosmetic outcome, and patient and surgeon preferences. Stapling does reduce surgical time, but is a more expensive option $[17,21,22]$.

Krishnan et al. [4] performed a meta-analysis and found that stapling had a higher incidence of SSI than suturing in elective and traumatic arthroplasties, but the inclusion was not limited to studies with a low risk of bias. It is unclear whether the SSI is associated with soft tissue reaction to stainless steel and titanium of staples, wound tension, the lack of perfusion, or poor techniques [21]. Overlapping or inverted wound edges may cause persistent oozing and infection at skin entry points [5, 23]. Several studies provided a description of stapling techniques $[12,13,17]$. One of them showed that wound oxygenation is similar in skin closure when subcuticular Vicryl or staples were used [13]. Theoretically, greater space between staples may provide an advantage in terms of oxygenation. Therefore, during wound closure, (1) the assistant should help prevent overlapping or inversion of the wound edges using toothed forceps, and (2) ensure enough spacing between staples (at least $6 \mathrm{~mm}$ ) $[5,13]$.

No difference between subgroups was found for continuous and interrupted sutures; however, the subgroup analysis was underpowered. Liu et al. [24] studied the differences between running absorbable and vertical mattress nonabsorbable sutures in total knee arthroplasty, and also showed no difference in infection rates. We therefore hypothesize that the suturing type may be less relevant than the ongoing debate between stapling versus suturing.
In hip arthroplasty, we found stapling was associated with an increased risk of SSI, compared to suturing. The underlying mechanism remains unclear but possibly involves a longer incision in knee arthroplasty, associated with more mobility than hip arthroplasty $[15,20]$. Suturing may be a preferential option to stapling in hip arthroplasty.

\section{Conclusion}

Stapling might carry a higher risk of surgical site infection than suturing in elective knee and hip arthroplasties, especially in hip arthroplasty.

\section{Abbreviations}

SSI: Surgical Site Infection; RR: Relative Risk; Cl: Confidence Interval; WHO: World Health Organization; RCT: Randomized Controlled Trial.

\section{Supplementary Information}

The online version contains supplementary material available at https://doi. org/10.1186/s42836-021-00110-7.

Additional file 1.

\section{Acknowledgements}

Not applicable.

\section{Authors' contributions}

AvdK was involved in research design, systematic literature search and literature assessment, data analysis and interpretation and writing of the article. RK was involved in research design, systematic literature search, data analysis and interpretation and writing of the article. WM was involved in research design and interpretation and writing of the article. LG was involved in systematic literature search and literature assessment, and writing of the article. BL was involved in systematic literature search and literature assessment, and writing of the article. JD was involved in research design, systematic literature search and literature assessment, and interpretation and writing of the article. TV was involved in research design and interpretation and writing of the article. JM was involved in research design, data analysis and interpretation and writing of the article. The author(s) read and approved the final manuscript.

\section{Funding}

Not applicable.

Availability of data and materials

No additional data are available.

\section{Declarations}

Ethical approval and consent to participate

Not applicable.

Consent for publication

All authors gave consent for publication in Arthroplasty.

\section{Competing interests}

All authors declare: We received no support from any organization for the submitted work; we had no financial relationships with any organizations that might have an interest in the submitted work in the previous 3 years, and no other relationships or activities that could appear to have influenced the submitted work. 


\begin{abstract}
Author details
${ }^{1}$ University of Groningen, University Medical Center Groningen, Groningen, The Netherlands. ${ }^{2}$ Department of Anesthesia \& Perioperative Medicine and Department of Epidemiology \& Biostatistics, MEDICI Centre, University of Western Ontario, London, Canada. ${ }^{3}$ Department of Orthopaedics, Joint Research, Onze Lieve Vrouwe Gasthuis, Amsterdam, the Netherlands. ${ }^{4}$ Department of Orthopaedics, University Medical Center Groningen, Postbus 30.001 9700 RB Groningen, The Netherlands. ${ }^{5}$ Department of Orthopaedics, Tergooi Hospital, Hilversum, The Netherlands.
\end{abstract}

Received: 16 October 2021 Accepted: 23 December 2021

Published online: 04 March 2022

\section{References}

1. Badia JM, Casey AL, Petrosillo N, Hudson PM, Mitchell SA, Crosby C. Impact of surgical site infection on healthcare costs and patient outcomes: a systematic review in six European countries. J Hosp Infect. 2017:96:1-15.

2. Berbari EF, Hanssen AD, Duffy MC, Steckelberg JM, Ilstrup DM, Harmsen WS, et al. Risk factors for prosthetic joint infection: case-control study. Clin Infect Dis. 1998;27:1247-54.

3. World Health Organization. Global guidelines on the prevention of surgical site infection. Geneva:WHO; 2016.

4. Krishnan RJ, Crawford EJ, Syed I, Kim P, Rampersaud YR, Martin J. Is the risk of infection lower with sutures than with Staples for skin closure after Orthopaedic surgery? A Meta-analysis of randomized trials. Clin Orthop Relat res Lippincott Williams and Wilkins. 2019:477:922-37.

5. Jonsson K, Jensen JA, Goodson WH, Scheuenstuhl H, West J, Hopf HW, et al. Tissue oxygenation, anemia, and perfusion in relation to wound healing in surgical patients. Ann Surg Lippincott Williams and Wilkins. 1991:214:605-13.

6. Mallee WH, Wijsbek AE, Schafroth MU, Wolkenfelt J, Baas DC, Vervest TMJS. Wound complications after total hip arthroplasty: a prospective, randomised controlled trial comparing staples with sutures. HIP Int SAGE Publications Ltd. 2020;00:1-6.

7. Higgins J, Thomas J, Chandler J, Cumpston M, Li T, Page M, et al. Cochrane Handbook for Systematic Reviews of Interventions. [Internet]. 2nd Editio. Chichester (UK):, editor. Updat. Sept. 2020. 2020.

8. Liberati A, Altman DG, Tetzlaff J, Mulrow C, Gøtzsche PC, loannidis JPA, et al. The PRISMA statement for reporting systematic reviews and metaanalyses of studies that evaluate healthcare interventions: explanation and elaboration. BMJ British Medical Journal Publishing Group. 2009;339.

9. Sterne J, Savović J, Page M, Elbers R, Blencowe N, Boutron I, et al. RoB 2: a revised tool for assessing risk of bias in randomised trials. BMJ. 2019;366:14898

10. Tufanaru C, Munn Z, Stephenson M, Aromataris E. Fixed or random effects meta-analysis? Common methodological issues in systematic reviews of effectiveness. Int J Evid based Healthc. Lippincott Williams and Wilkins. 2015;13:196-207.

11. Buttaro MA, Quinteros M, Martorell G, Zanotti G, Comba F, Piccaluga F. Skin staples versus intradermal wound closure following primary hip arthroplasty: a prospective, randomised trial including 231 cases. HIP Int Wichtig Publishing Srl. 2015;25:563-7.

12. Eggers MD, Fang L, Lionberger DR. A Comparison of Wound Closure Techniques for Total Knee Arthroplasty. J Arthroplasty. Churchill Livingstone Inc. 2011;26:1251-8 e4.

13. Graham D, Jeffery J, Bain D, Davies P, Bentley G. Staple vs. subcuticular vicryl skin closure in knee replacement surgery: a spectrophotographic assessment of wound characteristics. Knee. 2000;7:239-43.

14. Hlubek R, Walder P, Kána J, Šalounová D. Metal staples versus conventional suture for wound closure in total knee arthroplasty. Acta Chir Orthop Traumatol Cech. Galen s.r.o. 2014;81:233-7.

15. Khan RJK, Fick D, Yao F, Tang K, Hurworth M, Nivbrant B, et al. A comparison of three methods of wound closure following arthroplasty. A prospective, randomised, controlled trial. J Bone Jt Surg - Ser B. 2006;88:238-42.

16. Wyles CC, Jacobson SR, Houdek MT, Larson DR, Taunton MJ, Sim FH, et al. The Chitranjan Ranawat award: running Subcuticular closure enables the
Most robust perfusion after TKA: a randomized clinical trial. Clin Orthop Relat res Springer New York LLC. 2016;474:47-56.

17. Nepal S, Ruangsomboon $P$, Udomkiat $P$, Unnanuntana A. Cosmetic outcomes and patient satisfaction compared between staples and subcuticular suture technique for wound closure after primary total knee arthroplasty: a randomized controlled trial. Arch Orthop Trauma Surg Springer. 2020;140:1255-63.

18. Kim KY, Anoushiravani AA, Long WJ, Vigdorchik JM, Fernandez-Madrid I, Schwarzkopf R. A Meta-Analysis and Systematic Review Evaluating Skin Closure After Total Knee Arthroplasty-What Is the Best Method? [Internet]. J. Arthroplasty. Churchill Livingstone Inc. 2017:2920-7.

19. Krebs VE, Elmallah RK, Khlopas A, Chughtai M, Bonutti PM, Roche M, et al. Wound Closure Techniques for Total Knee Arthroplasty: An EvidenceBased Review of the Literature [Internet]. J. Arthroplasty. Churchill Livingstone Inc. 2018:633-8.

20. Smith TO, Sexton D, Mann C, Donell S. Sutures versus staples for skin closure in orthopaedic surgery: Meta-analysis. BMJ. BMJ Publishing Group. 2010;340:747.

21. Murphy M, Prendergast $P$, Rice J. Comparison of clips versus sutures in orthopaedic wound closure. Eur J Orthop Surg Traumatol. 2004:14:16-8.

22. Stockley I, Elson RA. Skin closure using staples and nylon sutures: a comparison of results. Ann R Coll Surg Engl Royal College of Surgeons of England. 1987;69:76-8.

23. Meiring L, Cilliers K, Barry R, Nel CJC. A comparison of a disposable skin stapler and nylon sutures for wound closure. South African Med J. 1982;62:371-2.

24. Liu S, Wang Y, Kotian RN, Li H, Mi Y, Zhang Y, et al. Comparison of nonabsorbable and absorbable suture in total knee arthroplasty. Med Sci Monit. International Scientific Information, Inc.; 2018;24:7563-9.

\section{Publisher's Note}

Springer Nature remains neutral with regard to jurisdictional claims in published maps and institutional affiliations.

Ready to submit your research? Choose BMC and benefit from

- fast, convenient online submission

- thorough peer review by experienced researchers in your field

- rapid publication on acceptance

- support for research data, including large and complex data types

- gold Open Access which fosters wider collaboration and increased citations

- maximum visibility for your research: over 100M website views per year

At BMC, research is always in progress.

Learn more biomedcentral.com/submissions 